\title{
SURVEY OF INDOOR NAVIGATION SOLUTIONS
}

\author{
Tamás Boros \\ MSc in Computer Science, University of Miskolc \\ Department of Information Technology, Institute of Information Technology \\ 3515 Miskolc, Miskolc-Egyetemváros, e-mail: function95@gmail.com
}

\begin{abstract}
In the last decade, there is an increasing demand for indoor positioning and navigation. These systems are beneficial in different areas of life, helping the people to find their way in the shopping mall, in the hospital or in any other building. As technology is continuously improving, new indoor systems are appearing bringing less costs and better performance, while other ones are becoming deprecated. This survey is an evaluation of the recent systems, taking their benefits and drawbacks into consideration and analysing the future tendencies.
\end{abstract}

Keywords: indoor navigation, positioning, location, way finding

\section{Introduction}

Navigation and positioning became significant parts of everyday life in the last decade [10]. Mobile devices are getting more widespread and this tendency provides ideal circumstances for them. We can distinguish two class of navigation systems: outdoor and indoor. Outdoor ones are excellent for car driving or any other activities outside. These systems based on GPS (Global Positioning System). Unfortunately many of us forget about indoor ones, however they can be applied at many areas: we can monitor the position of a piece of work being in preparation, we can help people suffering from disabilities (like blindness) to reach the desired destination faster. Moreover, there are so many cases when we cannot and a shop in a mall, an office or a room in a building. We can mention logistics as well, where it can be also useful. This essay bases on a similar study [4] of Vienna University of Technology, which was written in 2009. After some years, an updated survey is needed, as there are newly released indoor navigation and positioning systems. It is crucial to analyse the recent technologies, including the benefits and disadvantages. It is also a question if the outdoor support of these system has become better or not, even if they are indoor ones.

\section{Materials and Methods}

\subsection{NFC Internal}

In (Istanbul, Turkey) there is a Near Field Communication (NFC) based indoor navigation system called NFC Internal [5], which purpose to offer a passive indoor navigation system[11] with low cost. The main inspiration is to orient the user by a smartphone with integrated NFC component and an application running on it. The current position is determined by gathering data form NFC tags or in other words touching the mobile device to a tag. 


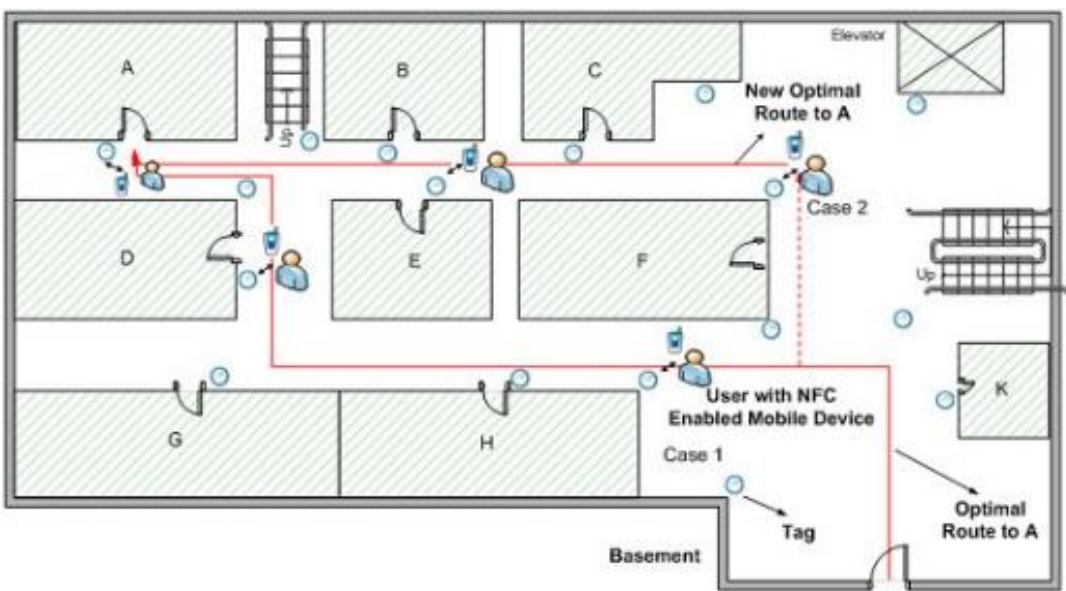

Figure 1: NFC Internal schematic structure [12]

NFC Internal system distinguish two sort of NFC tags with different aims. There is an URL tag, which contains the URL of the indoor map (floor plan). When a person enters a building and want to start the navigation, the mobile application needs this information. The map is downloaded from a webserver to the user's phone and after the application computes the route using Dijkstra' shortest path algorithm. The other tag is the Reference tag. The indoor environments have many of these: they are placed on the rooms', elevators' entrances and landmarks. These tags provide location information including floor identifier data, building identifier data and vector spatial data. The Reference tags can fix our current position on the map, reorient the position to destination, or even create a new route, if needed. The most significant advantage of the system is the simplicity and the low cost. NFC tags are quite cheap. It eliminates complicated infrastructure; the webserver is needed only to provide the maps to the guests. Because of this, location privacy is also guaranteed. If we should mention disadvantage, position cannot be provided on the go. The interaction with NFC tags is must be applied.

\subsection{Autonomous Multi-Floor Indoor Navigation with MAV}

There is an Autonomous Multi-Floor Indoor Navigation [6] system made by the University of Pennsylvania, where the experts use a micro aerial vehicle (hereinafter-called MAV) to navigate indoor fully autonomously. One of most significant advantages of the system is, it does not require external infrastructure, communication, or human interaction.

Every computation is made onboard: the MAV has a mobile CPU. This is an Intel $1.6 \mathrm{GHz}$ Atom processor with $1 \mathrm{~GB}$ of RAM. With this construction, it does multi-floor mapping, localization, planning, loop closure and control. The drone can be seen in figure 1 The drone has sensors as well: a laser sensor and a camera. On the MAV there is a $3 \mathrm{~d}$ printed mount attached to the laser and houses mirrors pointing upward and downward. The system supports multi-floor buildings and I mentioned loop closure. The latter one is when the robot observes a landmark for the second time, it corrects its position relative to the landmark position. During the flight, the drone creates a $2.5 \mathrm{D}$ environment model consisting of horizontal ground planes and vertical walls. The engineers try the drone at outside as well: it was able to localize but further development is required because it was not tested at unstructured environments like a park with trees. 


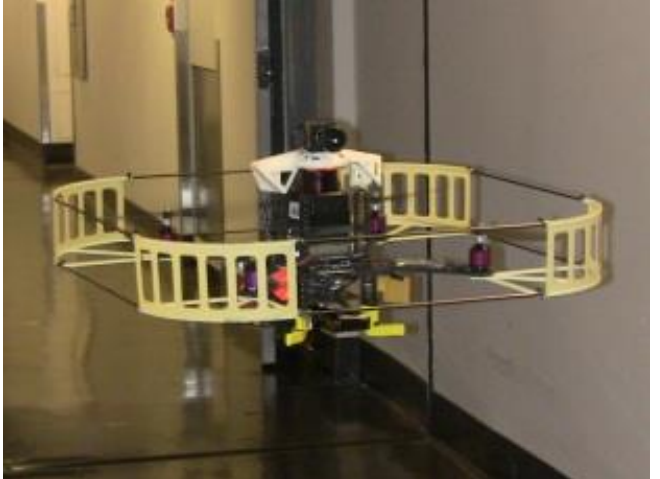

Figure 2: The MAV [6]

\subsection{NAvVis}

NAvVIS [7] is a camera-based indoor positioning system made by Technische Universität München. It is an accurate indoor positioning without any expensive infrastructure. The main idea is quite simple. There is a Mapping Trolley, which creates 3D images inside a current building and makes 2D maps. It has 6 high resolution system cameras and 3 high range $(30 \mathrm{~m})$ laser scanners. When a person comes into the building and takes images with his mobile device, the photos "are matched to previously acquired reference images. By determining the visually most accurate image, the position of the device is retrieved" [7]. To separate the images from each other, the system uses image signatures. They are created by BVLAD (Binary Vector of Locally Aggregated Descriptors). BVLAD is the modified version of VLAD computer vision algorithm specializing in image understanding and local features extraction and matching [13]. During the navigation, the user is helped by augmented reality as we can see in figure 2 .

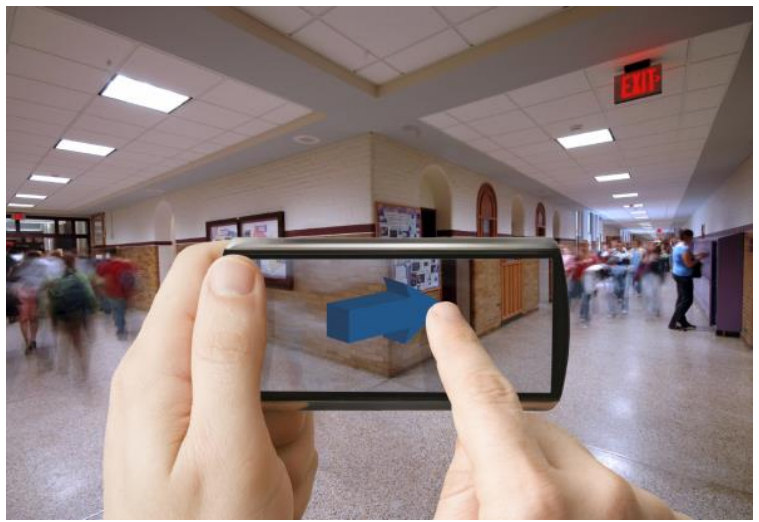

Figure 3: Vision-guided instructions [8]

\subsection{Magnetic-field based indoor navigation system by Tecnológico de Monterrey}

The purpose of indoor location project of Tecnológico de Monterrey[3] (a university in Mexico) was to create system which does not require a dedicated infrastructure (array of sensors, expensive access points). Without this, the system scalability can be cheaper, as it does not require adding equipment. The idea of engineers was to employ the irregularities of the earth's natural magnetic-field which is 
distributed by the building's structure and other objects in indoor environments. The irregularities mean the key for finding the location of the person. To detect these the experts, use smartphones with integrated magnetometer.

In several magnetic field based indoor location systems we must do a mapping beforehand, measuring the direction and the magnitude of the magnetic field. After the creation of this magnetic map, we use it for finding the location, finding the most similar place in the map to the one detected by the magnetometer.

The main advantage of this system is we just have to know in which room the person is located, instead of exact vector coordinates. We do not need to create a fully detailed map, measuring each point of the building. It is enough capturing a kind of signature taken from a random walk inside a room. This signature is the base component the frequency spectrum of the magnetic signal, taken from the Fourier transform of that signal.

The inventor could reduce by $90 \%$ the amount of information needed for the system and they managed to increase the specificity and sensitivity compared to the older project.

\subsection{IndoorAtlas}

Recently, a popular geomagnetical indoor system is IndoorAtlas [2, born in early 2012 in Oulu, Finland by Oulu University. It uses a sensor fusion algorithm combining sources of data relating to position with a basis in magnetic field sensing. Wi-Fi and other kind of radio signals are also used for rough position, where it is available.

This system requires floor plan and a previous measurement. During this sensor data is collected by a smartphone with integrated magnetometer, accelerometer and gyroscope [13]. Then the collected data is sent to the server. IndoorAtlas is a cloud service and the API are communicating with the cloud servers through the Internet.

It also able to work outdoors with steel structures such as sports stadiums, and the area immediately surrounding your building. It becomes less accurate when there are not any steel structures nearby (open areas like parks and squares). IndoorAtlas may be workable in an underground environment if it contains enough magnetic information. Moreover, experts successfully tested the technology in underground mining tunnels $(1400 \mathrm{~m}$ below the ground), where the metal ore is contributing to the magnetic irregularities.

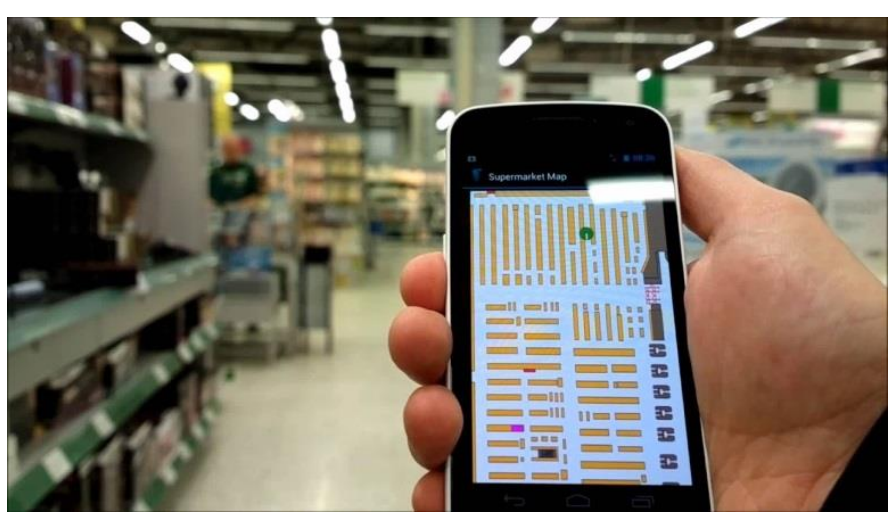

Figure 4: Navigating with IndoorAtlas[9] 


\section{Results}

1. Table Comparison of indoor navigation solutions

\begin{tabular}{|c|c|c|c|c|c|}
\hline Name & $\begin{array}{l}\text { Positioning } \\
\text { method }\end{array}$ & $\begin{array}{c}\text { Route } \\
\text { communication }\end{array}$ & $\begin{array}{c}\text { Client } \\
\text { platform }\end{array}$ & $\begin{array}{c}\text { Business } \\
\text { logic }\end{array}$ & Other \\
\hline NFC Internal & NFC & Map & Smartphone & Client & Low cost \\
\hline $\begin{array}{l}\text { Aut. multi- } \\
\text { indoor, MAV }\end{array}$ & $\begin{array}{l}\text { Laser range } \\
\text { finder, IMU }\end{array}$ & $\begin{array}{l}\text { Real-time } 2.5 \mathrm{D} \\
\text { maps }\end{array}$ & $\mathrm{PC}$ & $\begin{array}{c}\text { Onboard } \\
\text { (MAV) }\end{array}$ & \\
\hline NavVis & Camera-based & $\begin{array}{l}\text { Vision-guided } \\
\text { inst. }\end{array}$ & Smartphone & Server & \\
\hline $\begin{array}{l}\text { System of } \\
\text { Monterrey }\end{array}$ & Magnetic-field & Map & Smartphone & Server & $\begin{array}{l}\text { Detailed magnetic } \\
\text { map not needed }\end{array}$ \\
\hline IndoorAtlas & Magnetic-field & Map & Smartphone & Server & $\begin{array}{l}\text { With public magnetic- } \\
\text { map creator. }\end{array}$ \\
\hline $\begin{array}{l}\text { TRAVI- } \\
\text { NAVI }\end{array}$ & $\begin{array}{c}\text { Magnetic-field, } \\
\text { WIFI } \\
\text { fingerprinting, } \\
\text { Camera-based }\end{array}$ & $\begin{array}{c}\text { Pathway images, } \\
\text { Vision-guided } \\
\text { inst. }\end{array}$ & Smartphone & Server & Floor map not needed \\
\hline $\begin{array}{l}\text { ILONA- } \\
\text { Hybrid IPS }\end{array}$ & $\begin{array}{c}\text { Magnetic-field, } \\
\text { WIFI } \\
\text { fingeprinting } \\
\text { Bluetooth }\end{array}$ & Coordinates, text & Smartphone & Server & $\begin{array}{c}\text { Created at the } \\
\text { University of Miskolc }\end{array}$ \\
\hline
\end{tabular}

\section{Discussion}

Because of the rapid increase of mobile device production, most of indoor solutions bases on smartphone with integrated WIFI, magnetometer (digital compass) and camera. Probably, this will also lead to the quick spread of indoor navigation systems soon. It must be mentioned that camerabased projects have appeared, which initiates the help of camera and vision guided instructions into the navigation process. Thus, user interfaces have been friendlier and more comprehensible. NavVis is a great example of this. It would be also a good idea to extend the systems with voice instructions, but this is not a difficult task.

As for the technology, the most often used ones are WIFI fingerprinting and magnetic-field irregularities. They are more accurate than Infrared, ultrasonic system. The latter two technology beside others - have started to disappear as trilateration due to the mentioned problems.

In most cases, business logic is on the server side. Servers must return the location after finding the similar measurement data or picture. Servers are also needed to handle the database and the requests. As for the price NFC is the cheapest one, as it does not require large infrastructures or modifications in the environment (infrared and ultrasonic systems needed several changes). The systems are tending to be more simplified and optimized.

\section{Conclusion}

It was a long time for the humanity to start form the abacus and reach the era of navigation systems. These sorts of researches started in 1958, in the USA. The first system of the USA was the Transit. This was a rough system. Nowadays it is even possible to navigate in a supermarket, when we would like to buy our favourite product, or even help people with disabilities. Manufacturing can also make benefits from the use of these systems. We must admit the systems have been developed in the last 
few years, they are more accurate in positioning, cheaper. On the other hand, they have still problems. Before usage, they need previous work and maintenance. Maintenance means maintaining the server, the access points (i.e. at infrastructural changes). Experts also must optimize applications or response time. It will be interesting to see what kind of improvements will happen in the next few years and it would be great not to talk about indoor and outdoor navigation, just navigation, which handles any kind of area.

\section{References}

[1] http://www.vlfeat.org/. Accessed: 2019-11-05

[2] https://www.indooratlas.com. Accessed: 2019-11-05.

[3] Galván-Tejada, C.E., García-Vázquez, J.P., Brena, R.F. Magnetic feld feature extraction and selection for indoor location estimation. Sensors 2014,14(6):11001-11015. https://doi.org/10.3390/s140611001

[4] Huang, H., Gartner, G. A survey of mobile indoor navigation systems. In Cartography in Central and Eastern Europe, pp.305-319. Springer, 2009. https://doi.org/10.1007/978-3-642-03294-3_20

[5] Ozdenizci, B., Ok, K., Coskun, V., Aydin, M.N. Development of an indoor navigation system using nfe technology. In 2011 Fourth International Conference on Information and Computing, pp.11-14. IEEE, 2011. https://doi.org/10.1109/ICIC.2011.53

[6] Shen, S., Michael, N., Kumar, V. Autonomous multi-floor indoor navigation with a computationally constrained mav. In Robotics and automation (ICRA), 2011 IEEE international conference on, pp.20-25. IEEE, 2011. https://doi.org/10.1109/ICRA.2011.5980357

[7] Van Opdenbosch, D., Schroth, G., Huitl, R., Hilsenbeck, S., Garcea, A., Steinbach, E. Camerabased indoor positioning using scalable streaming of compressed binary image signatures. In 2014 IEEE International Conference on Image Processing (ICIP), pp.2804-2808. IEEE, 2014. https://doi.org/10.1109/ICIP.2014.7025567

[8] http://www.navvis.lmt.ei.tum.de/wp-content/uploads/2012/01/navi.jpg. Accessed: 2019-11-05

[9] https://venturebeat.com/2013/11/15/indoor-atlas-uses-magnetic-sensors-to-the-great-indoors/. Accessed: 2019-12-04

[10] Tóth, Zs. ILONA: indoor localization and navigation system, Journal of Location Based Services 2016,10(4):285-302. https://doi.org/10.1080/17489725.2017.1283453

[11] Deak, G., Curran, K., Condell, J. A survey of active and passive indoor localisation systems. Computer Communications 2012, 35(16):1939-1954.

https://doi.org/10.1016/j.comcom.2012.06.004

[12] Ozdenizci, B.; Coskun, V.; Ok, K. NFC Internal: An Indoor Navigation System. Sensors 2015, 15:7571-7595. https://doi.org/10.3390/s150407571

[13] Haverinen, J. Generating magnetic field map for indoor positioning. U.S. Patent No 9,080,874, 2015.

[14] Schroth, G. Visuelle Indoor-Navigation: Vom Forschungsprojekt Navvis zur NavVis GmbH. 2015. 